\title{
Formação de educadores: uma perspectiva de educação de idosos em programas de EJA*
}

\author{
Denise Travassos Marques \\ Pontifícia Universidade Católica de Campinas \\ Graziela Giusti Pachane \\ Universidade Federal do Triângulo Mineiro
}

\author{
Correspondência \\ Graziela Giusti Pachane \\ R. Cândida M. Bilharinho, 621, \\ apto. 102, bl. 02 \\ 38060-150 - Uberaba - MG \\ E-mail: grazielagp@yahoo.com.br
}

\section{Resumo}

0 objetivo deste estudo é salientar a necessidade de melhor formação docente em relação à Educação de Jovens e Adultos (EJA) e, mais especificamente, em relação ao idoso, um grupo marcado por múltiplas exclusões e bastante presente nas salas de aula de EJA. 0 estudo foi realizado a partir de revisão bibliográfica sobre Educação de Jovens e Adultos, idosos e formação docente, da reflexão sobre documentos, tais como a Constituição da República Federativa do Brasil e o Estatuto do Idoso, e da análise da experiência desenvolvida pela Secretaria Municipal de Educação de Campinas-SP, por meio da FUMEC (Fundação Municipal de Educação Comunitária). Após apresentar algumas perspectivas a respeito da ampliação no número de idosos na sociedade atual, dos preconceitos relacionados ao envelhecimento e da luta pelos direitos do cidadão idoso, focamos a importância do papel do educador no intuito de reverter a obscuridade a que é remetida a pessoa idosa, tanto no âmbito social quanto no educacional. Para tanto, concluímos, tornam-se necessárias rupturas, que dizem respeito à própria imagem do pedagogo e da área da educação na sociedade, notadamente vinculada à infância, no intuito de incluir temáticas relativas ao idoso e ao envelhecimento nos currículos dos cursos de pedagogia, bem como de ampliar discussões a respeito do idoso, em especial aquele oriundo de camadas populares, nas pesquisas no campo educacional.

\section{Palavras-chave}

Idosos - Cidadania - Formação docente - EJA.

\footnotetext{
* Gostaríamos de fazer um agradecimento a Alessandra Splendorelli, então secretária do Núcleo de Pesquisa e Extensão do Centro de Ciências Sociais Aplicadas da PUC-Campinas, por sua inestimável contribuição à publicação deste artigo.
} 


\title{
Teacher education: a view of the education of the elderly in EJA programs*
}

\author{
Denise Travassos Marques \\ Pontifícia Universidade Católica de Campinas \\ Graziela Giusti Pachane \\ Universidade Federal do Triângulo Mineiro
}

Contact:

Graziela Giusti Pachane

R. Cândida M. Bilharinho, 621, apto. 102, bl. 02

38060-150 - Uberaba - MG

E-mail: grazielagp@yahoo.com.br

\section{Abstract}

The objective of this study is to highlight the need for better teacher training with respect to the Education of Youngsters and Adults (EJA) and, more specifically, regarding the elderly, a group marked by multiple exclusions and strongly present in EJA classes. The study was based on a survey of the literatures on the Education of Youngsters and Adults, the elderly and teacher education, on the reflection on documents such as the Brazilian Constitution and the Statute of the Elderly, and on the analysis of the experience conducted by the Secretariat for Education of the City of Campinas (SP) through FUMEC (the Campinas Foundation for Community Education). After offering some ideas on the expansion of the number of elderly people in current society, on the prejudices related to growing old, and on the struggle for the rights of the elderly, we focus on the importance of the role of the educator to reverse the state of obscurity to which the elderly is relegated both in the social and in the educational spheres. To that end, we conclude for the need for ruptures regarding the image of the pedagogue and of the field of education in society, strongly linked to the childhood, with the aim of including themes related to the elderly and aging in the pedagogy curricula, as well as of stimulating the debate about the elderly, particularly those from the popular classes, in the field of educational research.

\section{Keywords}

Elderly people - Citizenship - Teacher education - EJA. 
No cotidiano das salas de aula da Educação de Jovens e Adultos (EJA) a presença de idosos é bastante frequente. Porém, podemos nos questionar se a formação oferecida ao pedagogo é suficiente e adequada para trabalhar com as necessidades específicas desse grupo, que podemos considerar duplamente excluído: primeiramente, por se encontrar numa faixa etária na qual, de maneira geral, o indivíduo não é mais economicamente ativo e, por outro lado, no caso específico da EJA, por se tratar de um grupo composto por pessoas iletradas, ou que tiveram pouco contato com a escola, geralmente oriundas de estratos sociais menos privilegiados.

Tendo em vista esse contexto, propomonos realizar um trabalho que visa compreender as especificidades do processo de envelhecimento, conhecer a participação do idoso em cursos de EJA e salientar a importância de que a formação dos educadores esteja voltada para o comprometimento com as questões sociais e com a dignidade humana, bem como às especificidades do idoso estudante na EJA.

Assim, abordamos no presente texto, elaborado a partir dos resultados da dissertação de mestrado realizada na Pontifícia Universidade Católica de Campinas (Marques, 2009), questões relativas a velhice, envelhecimento, o perfil desse segmento na sociedade moderna, cidadania e inclusão social.

0 estudo baseia-se na revisão bibliográfica sobre Educação de Jovens e Adultos (EJA), idosos e formação docente, e na análise de documentos, entre os quais salientamos o Projeto Político Pedagógico do Núcleo de Ação Educativa Descentralizada (NAED) Leste, da Fundação Municipal para Educação Comunitária (FUMEC) de Campinas, além da legislação mais ampla, como a Constituição Federativa do Brasil, o Estatuto do Idoso e as Leis do Município de Campinas em relação ao idoso.

Em suas conclusões, aponta a importância da formação continuada como meio de oferecer ao professor a atualização e a educação social necessária a fim de proporcionar uma formação de qualidade para os educandos idosos, segmento que não recebe atenção especial durante os programas de formação inicial (graduação) em pedagogia.

Devido à compreensão do papel da educação e, consequentemente, os educadores, como agentes de fundamental importância para a dignificação do idoso na sociedade, defendemos, inclusive, a necessidade de que temáticas sobre envelhecimento sejam abordadas durante a formação inicial desses profissionais, já nos cursos de pedagogia.

Esperamos que os aspectos aqui abordados possam subsidiar discussões a respeito da temática e oferecer alternativas de trabalho viáveis para o processo de inclusão social e educacional de parcela tão significativa da população brasileira, estigmatizada por uma história de múltiplas exclusões.

\section{Perspectivas sobre o envelhecimento: uma contextualização necessária}

A busca da longevidade sempre foi uma preocupação dos homens, intimamente ligada à capacidade física e relacionada à condição de produtividade social. A crescente melhoria nas condições de vida ao longo do tempo contribuiu para a ampliação do número de idosos na sociedade moderna. Porém, paradoxalmente, ao mesmo tempo em que se busca a longevidade, nega-se a velhice. De acordo com Py (2006):

As questões do envelhecimento suscitam grandes dúvidas, perplexidades, discussões. Interessam a todos nós, seres humanos envelhecendo. Interessam aos que já estão velhos e, também, aos adultos, aos jovens, às crianças que estão cursando esse processo. Nesse percurso, seguimos todos envelhecendo, com a tarefa humana de criar significações para os fatos que marcam a nossa existência. (p. 113-114)

Ainda que natural e irreversível (ou, talvez, justamente por isso), em nossa sociedade, o tema do envelhecimento tende a ser abordado de 
maneira sutil, em geral com uso de eufemismos para nomear a velhice, na tentativa de suavizar o peso que a palavra "velho" possui atualmente (Goldfarb, 1997). Ouve-se falar em "maior idade" ou "melhor idade"; o substantivo "velho" deu lugar para "senhor idoso", "senhor da terceira idade" ou "senhor de idade avançada", tanto no gênero masculino como no feminino; e o substantivo "velho" permanece apenas com função adjetiva, quando nomeamos coisas antigas ou usadas.

A palavra "velho" pode, no entanto, assumir distintos sentidos em distintas culturas e/ ou ambiências. Se, por um lado, pode trazer um sentido pejorativo, que carrega a imagem de algo decadente que está na hora de ser descartado, de alguém que não traz qualquer contribuição para o seu grupo social, ou de um ser dependente dos favores dos "capazes", em algumas culturas pode significar experiência. Como salienta Jeckel-Neto (2001) a respeito do envelhecimento:

Não existe apenas a ideia de decrepitude, como no português. Em inglês, por exemplo, existe a palavra old para velho, mas envelhecimento é aging. Essa palavra tem como radical age, ou idade, e não old. Na verdade, o sentido de aging é acrescentar idade. Em japonês, pode-se utilizar o termo karei. Ele é composto por [...] "ka" que é o radical do verbo kauwaeru, que significa somar, acrescentar, e "rei" que significa tempo de vida. (p. 41)

No presente trabalho, tendo em vista a utilização em inúmeras categorizações sobre esse "ser envelhecendo", optamos pelo termo idoso ao referirmo-nos às "pessoas que têm muita idade" (Ferreira, 1989, p. 349).

Apesar da relação com "idade avançada”, categorizar a velhice é uma atividade difícil, pois ela não consiste somente em um estado, mas sim em constante e sempre inacabado processo de subjetivação. Assim, na maioria das vezes, podemos dizer que não existe um "velho", mas sim um "ser envelhecendo".

Nesse sentido, Beauvoir (1976) salienta que a velhice só poderia ser compreendida em sua totalidade. Ela não representa somente um fato biológico, é também um fato cultural.

Envelhecer é um processo extremamente complexo (biológico, psicológico e social) e pouco conhecido entre os que o vivenciam, bem como para a sociedade de maneira geral. Sabemos que nessa fase da vida o corpo é mais frágil, requerendo mais cuidados, mas isso não anula a participação da pessoa na sociedade. Como destaca Freitas (2006):

Do ponto de vista fisiológico, o envelhecimento é caracterizado por uma limitação da capacidade de cada sistema em manter o equilíbrio do organismo. 0 declínio fisiológico tem início após a terceira década de vida, sofrendo a influência dos fatores genéticos, do meio ambiente e dos fatores de risco. Isso significa que podemos modificar, até certo ponto, as características do envelhecimento, agindo sobre esses fatores. Apesar de a maioria dos idosos apresentar pelo menos uma doença crônica, esse fato não necessariamente determina limitação para realização de suas atividades, desde que exista controle sobre a patologia ou patologias existentes, emergindo, de forma marcante, o conceito de capacidade funcional. (p. 26)

A idade, muitas vezes, é definidora das pessoas e submete-as a normas sociais que não as beneficiam, mas, ao contrário, as estigmatizam, negando sua individualidade. Sobre isso, Beauvoir (1976) pondera:

0 indivíduo é condicionado pela atitude prática e ideológica da sociedade a seu respeito. De modo que, uma descrição analítica dos diversos aspectos da velhice não pode ser suficiente: cada um deles reage sobre todos os outros e é por eles afetado. É o movimento indefinido desta circularidade que temos de aprendê-la. (p. 13-14)

Convém lembrar que o idoso nem sempre foi visto da maneira como é hoje, portanto, compreendê-lo como ator social produtivo é possibili- 
tar a compreensão do homem no tempo por meio da ambiência educativa de um povo. 0 mesmo se pode dizer do processo de envelhecimento.

A sociedade determina, segundo interesses convencionados, o lugar e o papel do idoso. 0 critério de idade não é o único usado por ela, mas reúne em si justificativas para a não valoração e não emancipação desse ator social. Tais justificativas atrelam-se aos arranjos sociais elaborados pela lógica do capital e seu centro de interesses, pautado pela produtividade e retorno econômico, que descartam aqueles que estão à margem desse quadro, entre eles, os idosos.

A complexidade da questão centra-se, portanto, na relação com a força de trabalho e com os meios de produção, conferindo ao idoso um papel determinado na sociedade, que, quando não caracterizado pelo desprezo, é marcado por um atendimento paliativo de suas necessidades.

A partir dos aspectos aqui expostos, observamos que é necessário compreender a velhice em sua totalidade, evidenciando aspectos biológicos e culturais, relacionados com a natureza humana, e através da história, em épocas distintas. Ou seja, um estudo sobre o aluno idoso, como nos propomos, precisa analisá-lo inserido em um contexto sócio-histórico, em um movimento de integração de relações políticas, econômicas, culturais, sociais e educacionais, muito além de suas capacidades físicas ou cognitivas.

\section{Envelhecimento populacional e construção da cidadania da pessoa idosa}

Nos países desenvolvidos, considera-se idoso o indivíduo com 65 ou mais anos. Já no Brasil, caracterizam-se como idosos indivíduos a partir de 60 anos. Nos países desenvolvidos, a preocupação com o envelhecimento populacional remonta ao início do século XX, enquanto nos países em desenvolvimento, entre eles o Brasil, essa preocupação pode ser percebida somente a partir de 1950.

Essas diferenças, segundo pesquisas de Kalache (1987), dão-se porque nos países de- senvolvidos há melhores condições de nutrição, saneamento, moradia e higiene pessoal, ambiente de trabalho, caracterizando melhor nível de vida, o que resultou no aumento da longevidade já na primeira metade do século passado, iniciando esse processo 50 anos antes do restante do mundo.

Os avanços da medicina a partir de meados do século passado (por exemplo, a descoberta de antibióticos e vacinas e a criação das unidades de terapia intensiva), bem como as mudanças no estilo de vida da população, foram fatores que contribuíram para maior expectativa de vida.

No mundo, o número de pessoas com idade igual ou superior a 60 anos tem aumentado rapidamente. Eram estimados 590 milhões de indivíduos nessa faixa etária no final do século passado. Em 2005, a projeção era de 1 bilhão e 200 milhões, com perspectiva de atingir 2 bilhões em 2050. Pela primeira vez na história da humanidade, o número de pessoas com mais de 60 anos superará o das crianças e jovens de 0 a 14 anos de idade, fenômeno que já aconteceu, segundo dados da ONU (1999), em países como Espanha, Japão e Alemanha.

O Brasil pertence ao grupo dos dez países com maior população de pessoas de 60 anos ou mais, em termos absolutos, segundo projeções populacionais das Nações Unidas, realizadas em 2005.

Segundo Freitas (2006), no Brasil, a maioria das pessoas idosas é do sexo feminino, seguindo a tendência mundial, com cerca de 100 mulheres pra 78,6 homens. Na região Sudeste, o sexo feminino apresenta maior sobrevida apenas nas áreas urbanas. É interessante observar ainda que, no Brasil, 1/3 dos homens idosos se encontram ativos no mercado de trabalho, muitos em razão da necessidade de continuar sustentando suas famílias.

Diante desse quadro de mudança no perfil da população mundial, o grande desafio da sociedade é conseguir aliar longevidade e qualidade de vida. Avanços tecnológicos, em especial aqueles aplicados à medicina, têm 
garantido melhor qualidade de vida aos idosos, no entanto, esse atendimento não se dá de modo igualitário, sendo grande a parcela da população idosa que vive em condições precárias, decorrentes, especialmente, de uma situação econômica desfavorável, da falta de instrução, do abandono ou da necessidade de realizar trabalhos "pesados" para garantir sua sobrevivência, entre outros aspectos.

Como salienta Goldman (2006), a população idosa tende a viver uma situação econômica problemática:

A desvalorização das aposentadorias e das pensões e os constantes aumentos no custo de vida, que não costumam acompanhar a correção anual dos benefícios previdenciários, contribuem sobremaneira para agravar o problema econômico dos idosos, pois a própria sobrevivência lhes parece ameaçada, principalmente se os gastos com a saúde forem muitos vultosos. (p. 59)

Como nos lembra Neri (2001), o aumento da população idosa, acompanhado da diminuição no número de nascimentos, dá origem a uma série de demandas, às quais a sociedade tem de responder:

A emergência de um novo grupo etário é comumente acompanhada de uma ideologia, da origem a necessidades e oportunidades sociais inéditas, condiciona o estabelecimento de novas políticas e práticas sociais e abre espaço para a criação de novas instituições e organizações sociais. (p. 20)

Observamos, portanto, que o envelhecimento populacional gera impactos sociais muito amplos, que repercutem na política financeira, levando a mudanças importantes na conduta social, como, por exemplo, em relação à Previdência Social, moradia, nutrição, saúde, educação, igualdade de oportunidades entre os sexos, entre outros.

Em grande parte do mundo, o tema do envelhecimento humano está na pauta de deba- tes sociais, políticos, econômicos, culturais, e em outras áreas que estão diretamente relacionadas aos idosos, como na saúde (Scharfstein, 2006).

A luta pela cidadania do idoso no Brasil tem constituído-se em objeto de discussões e encaminhamentos de inúmeros grupos, porém, muito ainda está por fazer.

Durante o Seminário Nacional Envelhecimento e Subjetividade, realizado no ano de 2008 em Brasília, Cristina Veras, psicóloga e membro do Conselho Nacional dos Direitos do Idoso, informou que teremos, em 2025, 40\% do total de idosos da América Latina. Essa é uma preocupação de vários profissionais especializados em terceira idade, pois o Brasil não está preparado para as demandas de tal número de idosos num futuro próximo.

Consideramos que deva haver debates entre diversos profissionais e gestores públicos sobre a necessidade de ampliar as políticas ligadas aos idosos, com objetivo de influenciar seu bem-estar e dignidade, principalmente dos economicamente desfavorecidos que são excluídos na sociedade.

Nesse sentido, é necessário considerar que, na sociedade capitalista, a vida econômica desloca-se para as atividades industriais, surgindo às relações sociais de base urbana e a categoria "ser cidadão" agrega-se à capacidade de ter direitos e deveres centrada na lógica de uma sociedade que faz apologia ao consumismo dos indivíduos, portanto, privilégio de poucos. No entanto, o conceito de cidadania, com o passar do tempo, vem ganhando outros contornos, surgidos de fermentações sociais reivindicando outro status, baseado na universalização de direitos, inclusive numa educação para a cidadania (Martins, 2000).

Em âmbito mundial, observamos que alguns países enfocam em suas Constituições a necessidade de defender os direitos dos idosos. Nesses casos, a velhice é tratada como direito constitucional a ser protegido, necessitando de amparo jurídico, legal e social.

Sousa (2004) realizou um estudo sobre alguns países nos quais as questões relativas às 
pessoas idosas são contempladas já na Constituição Federal. Segundo o autor, na América do Sul, Brasil, Peru, Uruguai e Venezuela dispõem de artigos sobre os direitos da pessoa idosa em suas Constituições. Na América Central somente Cuba traz alguma referência aos idosos em sua Constituição e na América do Norte apenas o México. Nenhum dos países africanos prevê regulamentação constitucional em relação ao idoso, o mesmo ocorrendo com a Oceania. $\mathrm{Na}$ Ásia somente a China faz referência ao idoso em sua lei maior e na Europa apenas Espanha, Itália, Portugal e Suíça possuem referência aos idosos em suas Cartas Magnas.

Assim, como podemos avaliar pelas informações de Sousa (2004), no mundo há poucos países que contemplam em suas constituições o direito do idoso.

A atual Constituição da República Federativa do Brasil (Brasil, 1988), prevê no Título VIII - Da Ordem Social, no Capítulo VII - Da Família, da Criança, do Adolescente e do Idoso, que

[...] a família, a sociedade e o Estado têm o dever de amparar as pessoas idosas, assegurando sua participação na comunidade, defendendo sua dignidade e bem-estar e garantindo-lhes o direito à vida. (art. 230)

A legislação brasileira está voltada, entre outros aspectos, à busca por mudanças no modo preconceituoso como o idoso muitas vezes é tratado, objetivando a sua integração à sociedade, auxiliando na obtenção de tratamento mais digno.

No caso específico do Brasil, além da Constituição, outro instrumento trata dos direitos do idoso no país: o Estatuto do Idoso.

0 Estatuto do Idoso, a que se refere a Lei n. 10.741/2003, é destinado a regular os direitos assegurados às pessoas com idade igual ou superior a 60 anos. É composto por 230 artigos, que tratam de saúde, transporte coletivo, violência e abandono, entidades de atendimento ao idoso, trabalho, habitação, lazer, cultura e esporte. Mais abrangente que a legislação anterior, a Política Nacional do Idoso, de 1994, o estatuto prevê penas severas para quem desrespeitar ou abandonar cidadãos idosos.

Entre os artigos que compõem o Estatuto do Idoso (Brasil, 2005), interessa-nos predominantemente o Título II, Dos Direitos Fundamentais, em seu Capítulo V, Da Educação, Cultura, Esporte e Lazer. Segundo o Estatuto,

[...] o idoso tem direito a educação, cultura, esporte, lazer, diversões, espetáculos, produtos e serviços que respeitem sua peculiar condição de idade. (art. 20)

Especificamente no que diz respeito à educação, o Estatuto do Idoso (Brasil, 2005) estipula que caberá ao Poder Público criar

[...] oportunidades de acesso do idoso à educação, adequando currículos, metodologias e material didático aos programas educacionais a ele destinados. (art. 21)

E, mais além, que os cursos para idosos incluirão conteúdo relativo às técnicas de comunicação, computação e demais avanços tecnológicos, visando sua integração à vida moderna.

Em seu art. 25, informa que o Poder Público apoiará a criação de universidade aberta para as pessoas idosas e incentivará a publicação de livros e periódicos de conteúdo e padrão editorial adequados ao idoso que facilitem a leitura considerando a natural redução da capacidade visual.

Por fim, no que tange à educação, indica que nos currículos de

[...] diversos níveis de ensino formal serão inseridos conteúdos voltados ao processo de envelhecimento, ao respeito e à valorização do idoso, de forma a eliminar o preconceito e a produzir conhecimentos sobre a matéria. (art. 22)

Paz (2006) afirma que envelhecer dignamente é direito do cidadão, vendo-se respeitado, não reduzido, projetado para uma nova 
consciência de compreensão do homem e não depreciado como objeto descartável no tempo. Nesse sentido, a legislação possibilita um grande avanço, pois prevê não apenas a garantia aos direitos dos idosos, mas, também, a educação das novas gerações para prepará-las a compreender o processo de envelhecimento.

$\mathrm{Na}$ sociedade atual, a construção da consciência cidadã por meio da educação possibilitaria a problematização de dimensões extremistas que impedem aos idosos o exercício pleno de sua cidadania.

Nessa perspectiva, consideramos fundamental o aspecto educativo, compreendendo que a educação é um passo fundamental à conscientização e à construção da cidadania, inclusive no sentido de compreender e acompanhar a efetivação das diretrizes expostas no Estatuto do Idoso.

Importa ressaltar que a importância da educação para o desenvolvimento da consciência cidadã, quer se manifeste no âmbito formal ou não formal do ensino, não se dá em si mesma, na prontidão da oferta da emancipação dos sujeitos e na apropriação de sua identidade social, mas, pelo contrário, é ponto de partida, provocação para uma ação reflexiva sobre o processo de historicidade do homem. A esse respeito, Demo (2001), alerta que:

A educação, na verdade, não opera nenhum milagre, como por vezes se imagina. Se bem conjugada com conhecimento crítico, aprendizagem reconstrutiva política e ética social oferecem elementos pertinentes para possível gestação de sociedades menos perversas. (p. 96)

Entendemos, portanto, que a educação é tanto um direto do idoso como um espaço privilegiado para a conscientização e um dos pilares para a construção de sua cidadania.

No mesmo movimento, acreditamos que a pesquisa científica na área da educação tem um papel muito importante a desempenhar: cabe a ela ampliar seus conhecimentos em relação ao tema, propondo investigações que possibilitem que questões relativas ao envelhecimento se tornem de interesse de toda a sociedade brasileira. Para isso, talvez algumas mudanças se façam necessárias.

\section{A quem o pedagogo conduz?}

Rupturas necessárias em um contexto de múltiplas exclusões

A perspectiva que vimos desenvolvendo, e que busca inserir a educação no cerne das ações para desenvolvimento da cidadania dos idosos, vai requerer uma série de rupturas. A primeira delas tem a ver com a própria representação social que se constrói do pedagogo.

A função do pedagogo está relacionada a todas as atividades de aprendizagem e de desenvolvimento humano, seja com crianças, jovens, adultos ou idosos, obedecendo ao perfil das instituições em que se encontram, pois o papel do pedagogo também existe longe da escola.

Muito embora sua área de atuação permita um caráter mais amplo, a formação do pedagogo é, de maneira geral, voltada à infância e à adolescência. Do idoso pouco se conhece, pois, afinal, desvincular sua imagem da escola e da criança é uma questão complicada, uma vez que a figura do pedagogo nasce vinculada ao velho escravo que, na Grécia Antiga, conduzia a criança para a escola.

Assim, como desde a antiguidade o papel do pedagogo está relacionado à infância, a introdução da formação de jovens e adultos já é uma ruptura em relação a essa imagem. Mais ainda ao pensarmos na formação do educador para lidar com as especificidades decorrentes do trabalho com idosos.

Há muitos estudos sobre a EJA atualmente, a exemplo de publicações de autores como: Álvaro Vieira Pinto, Leôncio José Gomes Soares, Vera Masagão Ribeiro, entre outros. Encontramse, também, trabalhos relativos à análise de educandos idosos, por exemplo, na Universidade Aberta à Terceira Idade (Cachioni, 1998; Dias, 2000; Erbolato, 2000; Oliveira, 2004; Arruda, 2009). Porém, quase nada tem sido produzido especificamente sobre os idosos na EJA. 
Lembramos que a expressão "Educação de Pessoas Jovens e Adultas" não nos remete apenas a uma questão de especificidade etária, mas, primordialmente, a uma questão de especificidade cultural. Os jovens e adultos são, basicamente, "não crianças". Além disso, o campo da educação não realiza reflexões e ações dirigidas a um jovem ou adulto específico, mas delimita um determinado grupo de pessoas relativamente homogêneo no interior da diversidade de grupos culturais da sociedade.

Refletir sobre como esses jovens e adultos pensam e aprendem envolve, portanto, transitar pelo menos por três campos que contribuem para a defınição de seu lugar social: a condição de "não crianças", a condição de excluídos da escola e a condição de membros de determinados grupos culturais.

No que diz respeito à condição de "não crianças”, Oliveira (2001) salienta que:

Esbarramos em limitação considerável da área da psicologia: as teorias sobre o desenvolvimento referem-se, historicamente, predominantemente à criança e ao adolescente, não tendo estabelecido, na verdade uma boa psicologia do adulto. Os processos de construção de conhecimento e de aprendizagem dos adultos são, assim, muito menos explorados na literatura psicológica do que aqueles referentes às crianças e aos adolescentes. (p.17)

É, portanto, uma área ainda bastante carente de estudos, sendo que, muitas vezes, as práticas pedagógicas realizadas com estudantes jovens e adultos limitam-se a uma abordagem eminentemente funcionalista (Peres, 2005), quase sempre voltada apenas à sua preparação para inserção no mercado de trabalho:

[...] a sociedade capitalista estruturou um sistema educacional e produtivo coerente aos seus interesses e relegou os idosos ao esquecimento. A criança deve ser educada para que, quando adulto, venha a ser um trabalhador adequado às necessidades do capital. 0 jovem e o adulto devem ser formados e profissionalizados para assumir uma função específica da esfera produtiva e garantir assim a eficiência do sistema econômico em constante desenvolvimento e mudança. E o velho? Onde entra? A verdade é dura é cruel: não há lugar para o velho na sociedade capitalista... (p. 89)

No que tange à especificidade da exclusão escolar dos jovens e adultos, importa destacar que a escola funciona com base em regras específicas e com uma linguagem particular que deve ser conhecida por aqueles que nela estão envolvidos. 0 desenvolvimento das atividades escolares está baseado em símbolos e regras que não são parte do conhecimento de senso comum. Isto é, o modo de se fazer as coisas na escola é específico da própria escola e aprendido em seu interior (Oliveira, 2001).

Assim, os educandos da EJA estão marcados pela exclusão social e, como exposto por Oliveira, também pela exclusão da cultura escolar. Nessa perspectiva, Marcon (2008) salienta que:

Notamos que os jovens que nunca frequentaram a escola têm um comportamento diferenciado daqueles que, de alguma forma, já passaram pelo ensino formal. Vários motivos os afastaram do mundo letrado. Mas mesmo com a falta de estudo, compreendemos que são pessoas com saberes produzidos na luta pela sobrevivência e marcadas pela exclusão social e econômica. (p. 100)

0 processo de exclusão da escola deixa os alunos em situação de desconforto devido a aspectos de natureza afetiva podendo, também, influenciar na aprendizagem. Os alunos geralmente têm vergonha de frequentar a escola depois de adultos. Pensam que serão os únicos em classes de crianças e, por isso, sentem-se humilhados. Muitos têm insegurança quanto à sua própria capacidade para aprender por conta da idade e sentem-se derrotados pelo estigma que carregam: 
Um dos nossos maiores desafios iniciais foi encontrar os analfabetos que vivem escondidos por entre a população letrada. Tais pessoas carregam consigo o estigma de uma situação da qual são vítimas, mas a consideram como derrota pessoal, por isso, sentem vergonha de participar de um grupo de alfabetização. (Campos, 2009, p. 74)

A referência ao lugar social ocupado pelos jovens e adultos, definido por sua condição de excluídos da escola regular, deve também ser examinada com relação a outros aspectos que os definem como um grupo relativamente homogêneo no interior da diversidade de grupos culturais da sociedade contemporânea.

0 grupo de estudantes de EJA é geralmente constituído por migrantes provenientes de áreas rurais empobrecidas que chegam às grandes metrópoles, filhos de trabalhadores rurais não qualificados e com baixo nível de instrução escolar, ou analfabetos; geralmente, esses indivíduos têm uma passagem curta e não sistemática pela escola. De maneira geral, trabalham em ocupações urbanas não qualificadas, após experiência no trabalho rural na infância e na adolescência. Buscam a escola tardiamente para alfabetizar-se ou cursar algumas séries do ensino supletivo.

0 idoso da EJA, portanto, tem sua história de vida marcada por diferentes situações de exclusão socialmente produzidas em uma sociedade desigual. 0 indivíduo é excluído não por ser diferente, mas por ser considerado não semelhante, uma pessoa à parte dos meios modernos de consumo. Com os efeitos da economia globalizada e da rápida mudança na era da informação, há uma aceleração e ampliação desse processo de exclusão social, pois as possibilidades de ação das camadas populares são limitadas.

Assim, à exclusão social, ao modo como adultos e jovens são objeto das práticas e reflexões educacionais, ao pouco conhecimento sobre os modos de construção de conhecimento dos adultos e aos fatores emocionais de um educando inseguro quanto a suas capacidades soma-se, no contexto da EJA, o problema do confronto entre diferentes culturas. Segundo Oliveira (2001), a escola voltada à formação de jovens e adultos é:

Ao mesmo tempo um local de confronto de culturas (cujo maior efeito é muitas vezes uma espécie de "domesticação" dos membros dos grupos pouco ou não escolarizados, no sentido de conformá-los a um padrão dominante de funcionamento intelectual) e, como qualquer situação de interação social, um local de encontro de singularidades. (p. 41)

Uma diversidade de atores e intervenções, além de um caráter aberto, têm feito da EJA um projeto político de inclusão. Nas palavras de Arroyo (2006):

A EJA sempre aparece vinculada a um outro projeto de sociedade, um projeto de inclusão do povo como sujeito de direitos. Foi sempre um dos campos da educação mais politizados, o que foi possível por ser um campo aberto, não fechado e nem burocratizado, por ser um campo de possiveis intervenções de agentes diversos da sociedade, com propostas diversas de sociedade e do papel do povo. (p. 31)

São, portanto, inúmeras responsabilidades, demandas, conflitos, esperanças e possibilidades que estão postas para a EJA, e que nos levam a refletir mais profundamente sobre as relações entre o idoso e o educador comprometido com o social.

\section{Educação e cidadania num contexto particular: a emergência de um educador comprometido com o social}

Consideramos de fundamental importância para nossas discussões situá-las mediante referência a uma situação concreta, realizando, para tanto, uma breve análise da experiência desenvolvida pela Secretaria de Educação de 
Campinas-SP e sobre a preparação dos educadores para o trabalho com o idoso em suas salas de EJA.

A cidade de Campinas possui legislação específica sobre o idoso, que trata de matérias referentes desde ao pagamento diferenciado de impostos até a programas de habitação, passando por condições de transporte e acessibilidade, programas de saúde, de lazer e cultura etc., sempre em consonância com o Estatuto do Idoso.

No entanto, observa-se, ainda, uma série de carências, uma vez que poucos são os locais em que os idosos podem ter acesso à computação e demais avanços tecnológicos, o mesmo dizendo respeito à publicação de livros, periódicos e dicionários adequados à leitura, já que os idosos, na maioria dos casos, sofrem de redução da capacidade visual.

No campo da educação, os idosos que não tiveram a oportunidade de frequentar a escola podem ser atendidos em programas vinculados à Secretaria Municipal de Educação.

Em 1987, após a extinção do MOBRAL e da Fundação Educar, foi criada em Campinas a FUMEC (Fundação Municipal de Educação Comunitária) que, a partir de 1991, passou a ter natureza jurídica de direito público. A Fundação destacou-se, desde o início, pelo envolvimento com a educação popular. Inicialmente preocupada com a criança em idade pré-escolar, a FUMEC, gradativamente, foi assumindo a função de trabalhar com EJA.

Devido ao tamanho da cidade de Campinas, a FUMEC é setorizada em NAEDs (Núcleos de Ação Educativa Descentralizada), sendo que o presente trabalho foi realizado a partir de dados da NAED Leste.

Diante das práticas assumidas pelos professores na época de sua criação, houve necessidade de se reorganizar e refletir sobre o currículo, as concepções de educação e metodologias utilizadas na Educação de Jovens e Adultos da FUMEC. Entre outras atividades, investiu-se na formação profissional em serviço, por meio de palestras, cursos de formação e assessoramento da Ação Educativa (Marcon, 2008).
A grande maioria de professores da FUMEC é constituída por docentes que assumiram classes de EJA sem terem sido devidamente preparados para isso. Assim, a FUMEC viu-se na obrigação político-pedagógica de assumir essa formação, fato que é descrito no próprio texto do Projeto Pedagógico da FUMEC (2007):

Nós educadores não fomos preparados no Magistério ou no curso de Pedagogia para trabalhar com a alfabetização de jovens e adultos, idosos, com alunos com necessidades especiais, liberdade assistida e alta vulnerabilidade. Sendo assim, vamos aprendendo através da prática pedagógica, do estudo e troca de experiências com colegas.

Muitas vezes somos como "pau pra toda obra". Sempre falta algo para melhorarmos profissionalmente. Somos como aprendiz que vai em busca de conhecimento para desenvolver um trabalho prazeroso, significativo e eficiente tanto para o professor quanto para o educando. Buscamos no dia a dia conhecer a realidade dos nossos educandos e com isso construir uma aprendizagem mais significativa. (p. 48)

Constatamos que é precária a formação inicial de muitos professores, o que é evidenciado não apenas pelos relatos registrados no Projeto Pedagógico, como também por uma breve análise dos currículos de formação dos pedagogos que atuam na EJA. A preparação para o trabalho com idosos é ainda mais precária, uma vez que demanda conhecimentos provenientes de outras ciências, como psicologia, medicina, nutrição e serviço social, aos quais os docentes nem sempre têm acesso.

Assim, a fim de possibilitar a capacitação dos professores para seu trabalho, a FUMEC busca realizar encontros, palestras e seminários que complementam as reuniões conduzidas pelos coordenadores pedagógicos, que têm características de um processo de formação continuada.

É importante destacar que a FUMEC conta com o TCD (Trabalho Docente Coletivo), um encontro semanal com duração de duas horas, 
que reúne os professores e o diretor regional. Durante esses encontros são realizadas trocas de experiências, ideias e materiais para enriquecer o trabalho em sala de aula. Embora muito positivo, o TDC, por ser setorizado, não permite que experiências das várias NAEDs sejam compartilhadas.

0 trabalho da FUMEC é realizado a partir de parcerias, sendo que os locais destinados a salas de aula são oriundos de convênios entre a Fundação e igrejas, escolas, albergues, empresas ou associações de bairro. É também dependente de parcerias o trabalho de alguns profissionais, como assistentes sociais, psicopedagogos e fonoaudiólogos (FUMEC, 2007).

0 perfil do educando de EJA da FUMEC é apresentado no trabalho de Marcon (2008):

A maioria dos alunos que frequenta as salas de aula, da FUMEC/NAED Leste, é migrante de zonas rurais do próprio estado de São Paulo. Temos muitos de outros estados. São filhos de pais também analfabetos, tendo já trabalhado na agricultura. Atualmente, exercem atividades profissionais ligadas ao comércio e demais serviços, tais como: ajudante de cozinha, pintor, serviços gerais, autônomo etc. Moram em bairros distantes do centro. Dispõem de pouco tempo para o lazer e possuem um nível socioeconômico baixo. Os que já tiveram na escola o fizeram por um breve período, pois muitas vezes tiveram de largar os estudos para ajudar a família. Outros porque os pais não viam necessidade de as filhas estudarem. (p. 99)

0 perfil etário dos educandos é bastante variado, porém, conta com um amplo contingente de idosos, como pode ser observado pelo Projeto Pedagógico da FUMEC (2007):

A faixa etária dos educandos, deste NAED, é bem abrangente contempla desde os 14 completos e, às vezes com idade menor que a exigida pelo nosso Regimento desta Fundação devido ao Conselho Tutelar, até 92 anos... Temos a especificidade dos alunos da Casa-
Escola, em que a idade dos mesmos varia entre 30 e 70 anos, com média de internação psiquiátrica de 30 anos. (p. 34)

Isso demonstra a complexidade da atividade realizada pelos docentes, que necessitam trabalhar com jovens, adultos trabalhadores, idosos, pessoas com necessidades especiais, pessoas em liberdade assistida, enfım, pessoas que, de alguma maneira, encontram-se em situação de vulnerabilidade.

Aspectos que, a nosso ver, reforçam a importante função dos educadores de EJA dentro da sociedade, devendo estes estar cientes do significado social e político de suas atitudes.

Entendemos que o compromisso com a humanização como possibilidade concreta exige a formação de educadores éticos, seres de opção e de decisão que possam se comprometer com os interesses emancipatórios da população idosa e a construção de uma sociedade mais justa e menos desigual.

Nessa perspectiva, é importante ressaltar a importância do processo de conscientização para o educador comprometido com a transformação social, que não pode ser um profissional neutro diante do mundo em seu trabalho político-pedagógico, pois, concordando com Paulo Freire (1980), quanto mais conscientizados nos tornamos, mais capacitados estamos para ser anunciadores e denunciadores, graças ao compromisso de transformação que assumimos.

Isso nos leva a refletir, em primeiro lugar, que num contexto em que o lugar social ocupado pelos educandos idosos é de exclusão, o professor tem que tornar o ambiente de sua aula desafiador, porém, ao mesmo tempo, precisa conseguir que seus alunos acompanhem as idas e vindas do pensamento, no movimento dialógico e de despertar da curiosidade que deve ocorrer na sala de aula, conforme salientado por Paulo Freire (2000):

0 fundamental é que o professor e alunos saibam que a postura deles, do professor e dos alunos, é dialógica, aberta, curiosa, in- 
dagadora e não passivada, enquanto fala ou enquanto ouve. 0 que importa é que professor e alunos se assumam epistemologicamente curiosos. (p. 96)

Leva-nos, também, a compreender que a formação docente e o compromisso social do educador são fundamentais para superação de práticas sociais articuladas aos interesses de uma elite como instrumento de poder e exploração dos seres humanos.

Entendemos que professores de EJA deveriam, portanto, atuar a partir da ótica de educadores sociais, isto é, trabalhar para superar os obstáculos a fim de proporcionar uma educação de qualidade para todos.

Segundo Caro e Guzzo (2004), o Educador Social é responsável pela intervenção sócio-educativa, com capacidade de dinamizar os grupos por meio do contexto social, por meio de educação não formal.

Aqui, destaca-se uma característica bastante importante da educação não formal: ela tem potencialidades para o exercício da função social de escola, evitando contradições e jogos entre interesses pessoais e sociais, mais até que a educação formal, a qual muitas vezes preserva os interesses de determinada parcela da sociedade e anula a pluralidade cultural, perdendo, assim, seu sentido de função social, aspecto que nos leva às palavras de Arroyo (2006), citadas anteriormente, quando tratamos da EJA: uma educação vinculada a um outro projeto de sociedade, um projeto de inclusão do povo como sujeito de direitos, um campo de possíveis intervenções de agentes diversos da sociedade, com propostas diversas de sociedade e do papel do povo.

Assim, projetos como os realizados pela FUMEC, embora certifiquem seus alunos do mesmo modo que cursos de educação formal, são oportunidades de educação comunitária, uma vez que, pelos espaços onde são realizados, pela população a que atendem e pela atenção dedicada às especificidades de seus educandos, permitem atingir um objetivo mais amplo: a construção de uma nova consciência na comunidade, nos termos propostos por Chinelli (apud Caro; Guzzo, 2004).

Ao atentar para as especificidades do público atendido e levando em conta o alto contingente de idosos nas salas de aula de educação popular, consideramos de suma importância por parte dos educadores da EJA o conhecimento das potencialidades e necessidades desse grupo, o que passa, entre outros aspectos, pelo conhecimento de suas condições físicas e psicológicas, bem como de suas especificidades culturais.

Estar preparado para trabalhar com o idoso compreende, ainda, o conhecimento da legislação pertinente, em especial o Estatuto do Idoso, como também a sua discussão com os alunos e com a sociedade de maneira geral, a fim de alcançar os objetivos propostos pela lei, assegurando direitos fundamentais inerentes à pessoa humana.

Acreditamos que os educadores deveriam tomar ciência de tais leis, proporcionando e facilitando uma melhora no relacionamento entre os educandos idosos com outras faixas etárias e proporcionando um convívio mais justo nos diversos contextos da nossa sociedade.

Tais leis, bem como especificidades a respeito do trabalho com idosos, poderiam ser abordadas no curso de pedagogia, contribuindo na formação do professor comprometido com o social e com a diminuição das desigualdades e injustiças a que é submetida grande parcela dos idosos. Acreditamos, ainda, que os próprios alunos idosos, professores de EJA e pedagogos, de maneira geral, deveriam frequentar fóruns para discussão sobre políticas e leis relativas à velhice, além de fomentar sua realização.

Dessa forma, a EJA e a educação popular teriam possibilidade de obter o buscado sentido emancipador, por meio de uma prática educativa dialética de conhecimentos entre educandos e educadores e do oferecimento de significativa contribuição para a efetivação das propostas do Estatuto do Idoso, em especial no que diz respeito aos itens expostos no Título II do Capítulo V, relativos ao direito a educação, 
lazer, cultura, currículos e materiais didáticos adequados a suas necessidades, bem como a inserção de conteúdo a respeito do envelhecimento nos diferentes níveis de escolarização.

\section{Considerações finais}

0 estudo realizado teve como objetivo salientar a necessidade de melhor formação docente em relação à Educação de Jovens e Adultos e, mais especificamente, em relação ao idoso, um grupo marcado por múltiplas exclusões e bastante presente nas salas de aula de EJA.

Ao longo do texto, destacamos a importância do docente conhecer a legislação a respeito do idoso, bem como de compreender algumas características gerais do processo de envelhecimento; porém, acrescentamos, sem deixar de atentar para as especificidades de cada educando e para sua trajetória de vida nos momentos em sala de aula.

A partir de alguns aspectos aqui discutidos acerca das múltiplas exclusões vivenciadas pelos idosos de EJA, enfatizamos a necessidade de enfrentamento e comprometimento por parte de seus docentes, uma vez que a sociedade capi- talista visa o atendimento do sistema produtivo. Dessa forma, no sentido de resgatar a dignidade e propiciar a inserção dos idosos das classes populares na sociedade, de maneira cidadã, é necessário que os docentes de EJA assumam-se como "educadores sociais".

E assumir-se nessa perspectiva pressupõe um conjunto de rupturas, que se iniciam com a imagem normalmente associada ao pedagogo e à área de educação, de que seu foco é apenas a formação da infância.

É uma tarefa árdua, porém, necessária, diríamos até emergencial. Embora educação e envelhecimento tenham sido dois temas muito evidenciados na contemporaneidade por meio de pesquisas, discursos e políticas públicas, faz-se necessário ampliar a articulação entre essas duas temáticas e compreender mais a fundo o itinerário do envelhecimento, enquanto categoria social e histórica, para desvelarmos os seus sentidos e encaminhamentos possíveis, entre os quais destacamos um posicionamento político que se sustente na dignificação do idoso como ator social, investido, portanto, de uma identidade cidadã, que se faz relegada a segundo plano, muitas vezes pela conveniência de seu esquecimento. 


\section{Referencias bibliográficas}

ARROYO, M. G. Educação de jovens e adultos: um campo de direitos e de responsabilidade pública. In: SOARES, L. et al. Diálogos na educação de jovens e adultos. 2. ed. Belo Horizonte: Autêntica, 2006. p. 19-50.

ARRUDA, I. Análise de uma universidade da terceira idade no município de Campinas. 2009. Dissertação (Mestrado)Pontifícia Universidade Católica de Campinas, Campinas, 2009.

BEAUVOIR, S. A velhice. Rio de Janeiro: Nova Fronteira, 1976.

BRASIL. Constituição da República Federativa do Brasil. Brasilia: Senado Federal, 1988. Disponível em: <http://www.planalto. gov.br/ccivil_03/Constituicao/Constituiçao.htm>. Acesso em: 8 jun. 2010.

Estatuto do Idoso. Coord. André Arruda. Rio de Janeiro: Roma Victor, 2005.

CACHIONI. M. Envelhecimento bem-sucedido e participação numa universidade para a terceira idade: a experiência dos alunos da Universidade São Francisco. 1998. Dissertação (Mestrado)- Pontifícia Universidade Católica de Campinas, Campinas, 1998.

CAMPOS, A. M. Diálogos com quem ousa educar, educando-se: a formação de educadores a partir de uma experiência de Educação Popular. 2009. Dissertação (Mestrado)- Pontifícia Universidade Católica de Campinas, Campinas, 2009.

CARO, S. M. P.; GUZZO, R. S. L. Educação social e psicologia. Campinas: Alínea, 2004.

DEMO, P. Cidadania pequena: fragilidade do associativismo no Brasil. Campinas: Autores Associados, 2001. (Coleção Polêmica do Nosso Tempo, n. 80.)

DIAS, M. C. Avaliação de um projeto pedagógico de uma Universidade da Terceira Idade: múltiplos olhares e vozes. 2000. Dissertação (Mestrado)- Pontifícia Universidade Católica de Campinas, Campinas, 2000.

ERBOLATO, R. M. Gostando de si mesmo: a autoestima. In: NERI, A. L; FREIRE, A. S. (Orgs.). E por falar em boa velhice. Campinas: Papirus, 2000.

FERREIRA, A. B. H. Dicionário Aurélio básico da língua portuguesa. Rio de Janeiro: Nova Fronteira, 1989.

FREIRE, P. Educação como prática da liberdade. 8. ed. Rio de Janeiro: Paz e Terra, 1978.

Conscientização: teoria e prática da libertação. 3. ed. São Paulo: Moraes, 1980.

Pedagogia da autonomia. 12. ed. Rio de Janeiro: Paz e Terra, 2000.

FREITAS, E. V. Demografia e epidemia do envelhecimento. In: PY, L. et al. Tempo de envelhecer: percursos e dimensões psicossociais. 2. ed. Holambra: Setembro, 2006. p. 15-38.

FUNDAÇÃO MUNICIPAL DE EDUCAÇÃO COMUNITÁRIA (FUMEC). Projeto pedagógico. Campinas: Núcleo de Ação Educativa Descentralizada (NAED) Leste, 2007.

GOLDFARB, D. C. Corpo, tempo e envelhecimento. 1997. Dissertação (Mestrado)- Pontifícia Universidade Católica de Campinas, Campinas, 1997.

GOLDMAN, S. N. As dimensões sociopolíticas do envelhecimento. In: PY, L. et al. Tempo de envelhecer: percursos e dimensões psicossociais. 2. ed. Holambra: Setembro, 2006. p. 57-76.

JECKEL-NETO, E. A. Torna-se velho ou ganhar idade: 0 envelhecimento biológico revisitado. In: NERI, A. L. (Org.). Desenvolvimento e envelhecimento: perspectivas biológicas, psicológicas e sociológicas. Campinas: Papirus, 2001. p. 39 -52 (Coleção Vivaidade.)

KALACHE, A.; VERAS, R. P.; RAMOS, L. R. The aging of the world population: a new challenge. Revista de Saúde Pública, v. 21 n. 3, p. 200-210, 1987.

MARCON, E. P. B. Fundação Municipal para Educação Comunitária. In: SALAZAR, A. G. T. et al. Projeto Casa-Escola: a concretização de um sonho. Campinas: Prefeitura Municipal de Campinas/FUMEC Cândido Ferreira, 2008. p. 85-106.

MARQUES, D. T. Educação de jovens e adultos: uma perspectiva de alfabetização com idosos. 2009. Dissertação (Mestrado)Pontifícia Universidade Católica de Campinas, Campinas, 2009.

MARTINS, M. F. Uma "catarsis" no conceito de cidadania: do cidadão cliente à cidadania com valor ético-político. Revista Ética, Campinas, v. 2, n. 2, p. 106-118, jul./dez. 2000.

NERI, A. L. (Org.). Desenvolvimento e envelhecimento: perspectivas biológicas, psicológicas e sociológicas. Campinas: Papirus, 2001. (Coleção Vivaidade.)

OLIVEIRA, M. K. Jovens e adultos como sujeitos de conhecimento e aprendizagem. In: RIBEIRO, V. M. (Org.). Educação de jovens e 
adultos: novos leitores, novas leituras. Campinas/São Paulo: Associação de Leitura do Brasil/Mercado de Letras/Ação Educativa, 2001. p. 15-43. (Coleção Leituras no Brasil)

OLIVEIRA, V. R. A construção da relação professor-aluno em uma Universidade da Terceira Idade. 2004. Dissertação (Mestrado)- Pontifícia Universidade Católica de Campinas, Campinas, 2004.

ORGANIZAÇÃO DAS NAÇÕES UNIDAS (ONU). Population ageing. New York: United Nations Population Division, 1999.

. Ageling: society for all ages policy framework. Disponível em: <http://www.un.org/esa/socdev/cigeing/agepframe.htm>. Acesso em: 20 jul. 2003.

PAZ, S. F. Movimentos sociais: participação dos idosos. In: PY, L. et.al. Tempo de envelhecer: percursos e dimensões psicossociais. 2. ed. Holambra: Setembro, 2006. p. 229-256.

PERES, M. A. C. A andragogia no limiar da relação entre velhice, trabalho e educação. Revista Educação e Cidadania, v. 4, n. 2, p. 87-94, 2005.

PINTO, A. V. Sete lições sobre educação de adultos. 10. ed. São Paulo: Cortez, 1997.

PREFEITURA MUNICIPAL DE CAMPINAS. Idoso. Disponível em: <http://www.campinas.sp.gov.br/bibiuri/cidadania.htm>. Acesso em: 8 dez. 2008

PY, L. Envelhecendo e subjetividade. In: PY, Ligia et al. Tempo de envelhecer: percursos e dimensões psicossociais. 2. ed. Holambra: Setembro, 2006. p. 97-120.

RIBEIRO, V. M. (Org.). Educação de jovens e adultos: novos leitores, novas leituras. Campinas/São Paulo: ALB/Mercado de Letras/ Ação Educativa, 2001.

SCHARFSTEIN, E. A. Intervenção psicossocial. In: PY, Ligia et al. Tempo de envelhecer: percursos e dimensões psicossociais. 2. ed. Holambra: Setembro, 2006. p. 273-292.

SOARES. L.; GIOVANETTI, M. A.; GOMES, N..L. (Org.). Diálogos na educação de jovens e adultos. 2. ed. Belo Horizonte: Autêntica, 2006.

SOUSA, A. M. V. Tutela jurídica do idoso: a assistência e a convivência familiar. Campinas: Alínea, 2004.

VERAS. C. Brasil terá $\mathbf{4 0 \%}$ dos idosos da América Latina em 2025. Disponível em: <http://noticias/com/s/22112008/25/ manchetes-brasil-tera-40-dos-idosos.html>. Acesso em: 8 dez. 2008.

Recebido em 05.03.09

Aprovado em 04.05.10

Denise Travassos Marques é mestre em Educação, na área de Formação de Professores, pelo Programa de Pós-Graduação em Educação (PUC-Campinas). Pós-Graduação lato sensu em Educação Social (UNISAL-Campinas) e Sociopsicomotricidade (FAHUPE-RJ). Graduação em Pedagogia (PUC-Campinas) e Direito (Universidade Cândido Mendes - Rio de Janeiro). Professora de EJA (FUMEC).

Graziela Giusti Pachane é mestre e doutora em Educação pela Unicamp, graduada em Letras pela mesma universidade. Foi professora do Programa de Pós-Graduação em Educação da PUC-Campinas e atualmente é docente na UFTM (Universidade Federal do Triângulo Mineiro), em Uberaba-MG. 